\title{
A study on relationship between creativity and idealistic realistic attitude: A case study of high school teachers
}

\author{
Syed Habib Maktabi ${ }^{\mathrm{a}}$, Fariba Hanifi ${ }^{\mathrm{b}}$ and Maryam Feizabadi ${ }^{\mathrm{c}^{*}}$
}

${ }^{a}$ Faculty of Educational Sciences, Qeshm Branch, Islamic Azad University, Qeshm, Iran

${ }^{b}$ Faculty of Educational Sciences, Roudehen Branch, Islamic Azad University, Roudehen, Iran

${ }^{c}$ Masters Student of Educational Administration, Qeshm International Unit, Iran

\begin{tabular}{l}
\hline A R T I C L E I N F O \\
\hline Article history: \\
Received January 20, 2013 \\
Received in Revised form \\
March, 26, 2013 \\
Accepted 17 June 2013 \\
Available online \\
18 June 2013 \\
\hline Keywords: \\
Creativity \\
Idealistic realistic attitude \\
High school teachers
\end{tabular}

\section{A B S T R A C T}

\begin{abstract}
This paper presents a study to investigate the relationship between creativity and idealistic realistic attitude among high school teachers in city of Gorgan, Iran over the years 2010-2011. The study designs a questionnaire in Likert scale and distributes it among 262 randomly selected teachers. Cronbach alphas have been calculated as 0.88 and 0.876 for creativity and idealistic, respectively. The results of the survey indicate that there was a significant correlation between teachers' creativity and their realistic and idealistic approach. The study also finds out that teachers' with realistic \& idealistic approach are more creative than those who are not. In our survey, idealist teachers are more creative than realist teachers are and there is a significant relationship between teachers' gender and their realistic and idealistic approach.
\end{abstract}

(c) 2012 Growing Science Ltd. All rights reserved.

\section{Introduction}

Creativity normally helps teachers resolve many unexpected incidents and assist them build a beter teaching environment (Blumen-Pardo et al., 2002; Crowther et al., 2008). According to Smith (2005) "the very task of writing about these events is a creative process and takes the author and reader into unexpected directions, yielding more ideas about the nature of educational idealism, realism, and school reform”. Young, B.J. (1995) examined the reasons for entry, work perceptions, and the future career plans of 272 teachers who entered a highly selective graduate teacher education program over the period 1987-1988. Their job expectations were compared with a sample of experienced teachers and reported that these talented students were entering the profession mainly for altruistic reasons and had fairly realistic views of working conditions. However, many plan to remain only if they derive the expected satisfaction from working which children. They compared their results to labor market predicting theories to attract and retain high ability individuals to the teaching profession. 
Rampaul (1984) studied the relationship between academic achievement, self-concept, creativity, and teacher expectations among Native children in a northern Manitoba school. The study reported significant positive correlations among self-concept, academic achievement, and teacher expectations and low positive relationship between creativity and academic achievement. Wiggins (1999) investigated the relationship between teacher's control and creativity and concluded that it is possible for teachers to design and carry out compositional projects in ways that enable students to become initiatives. Troman et al. (2007) investigated creativity and performativity policies in primary school cultures.

\section{The proposed study}

The proposed study of this paper studies the relationship between creativity and idealistic-realistic behaviors among teachers who work in some Iranian high schools located in city of Gorgan, Iran. The study designs a questionnaire consists of 60 questions associated with creativity and 29 questions, which are related to idealistic-realistic behavior. There were 465 female and 356 male teachers and the study uses the following relationship to determine the sample size,

$$
n=\frac{N \times z_{\alpha / 2}^{2} \times p \times q}{\varepsilon^{2} \times(N-1)+z_{\alpha / 2}^{2} \times p \times q},
$$

where $N$ is the population size, $p=1-q$ represents the yes/no categories, $z_{\alpha / 2}$ is CDF of normal distribution and finally $\varepsilon$ is the error term. Since we have $p=0.5, z_{\alpha / 2}=1.96$ and $N=465$ for female teachers and $\mathrm{N}=356$ for male teachers, the sample sizes are calculated as $n=148$ and $n=114$ for female and male group, respectively. We have selected 30 teachers, distributes questionnaire among them and calculated Cronbach alpha. The results of Cronbach alphas for creativity and idealisticrealistic questionnaires were 0.88 and 0.876 , respectively, which are well above the minimum acceptable limits. This valdates the overal questionnaire and we can proceed the next step. The collected data from questionnaire were analyzed using descriptive statistics methods, including domain, mode, median, mean, variance, standard deviation, skewness and kurtosis coefficient and inferential statistics including kolmogorov - smirnov test to identify the normality of data, Spearman correlation, Pi and regression were analyzed through SPSS software.

\section{The results}

\subsection{Inferential analysis of data}

We first use Kolmogorov-Smirnov test to verify the normality of data. The results of this test are presented in Table 1 as follows,

\section{Table 1}

Results of data normality test

\begin{tabular}{llcc}
\hline & & Idealism & Realism \\
\cline { 3 - 4 } Number & & 262 & 262 \\
\hline Natural parameters & Mean & 49.045 & 47.1412 \\
& Standard deviation & 13.54 & 13.45 \\
\hline Standard deviation & Absolute & 0.056 & 0.063 \\
\hline Difference & Positive & 0.046 & 0.063 \\
& Negative & -0.056 & 0.050 \\
\hline Kolmogorov-Smirnov & & 0.899 & 1.025 \\
Significant level & & 0.394 & 0.244 \\
\hline
\end{tabular}

Based on the results of Table 1, we can conclude that all data are normally distributed when the level of significance is five percent. Therefore, we perform linear regression analysis to test different hypotheses of the survey. 


\subsection{The first hypothesis: relationship between creativity and being realistic-idealistic}

The first hypothesis of this survey investigates whether there is any relationship between Gorgan High schools teacher's creativity and their Realistic \& Idealistic approach or not. To answer this question we perform a regression analysis and Table 2 summarizes the results of our survey.

\section{Table 2}

The summary of regression test to examine the relationship between creativity and realistic sense

\begin{tabular}{|c|c|c|c|c|c|}
\hline & \multicolumn{5}{|c|}{ Dependent variable to creativity } \\
\hline & $\mathrm{B}$ & Estimate Standard error & ß 's Standardized coefficients & $\mathrm{T}$ & Sig. \\
\hline Constant number & 146.625 & 12.273 & & 11.947 & 000 \\
\hline Idealism Attitude & 0.184 & 0.143 & 0.087 & 2.280 & 0.022 \\
\hline Realism Attitude & -0.708 & 0.144 & -.0 .335 & -4.903 & 000 \\
\hline
\end{tabular}

$\mathrm{R}^{2}=0.152$ Adjusted $\mathrm{R}^{2}=0.145 \mathrm{~F}=23.145$ Significant level $=000 \mathrm{R}=0.389$

According to the results of Table 2, the amount of $\mathrm{R}^{2}$ implies that $15 \%$ of creativity variance changing is justified by attitude variables of idealist and realist. Furthermore the ratio of calculated $F$ is significant in $99 \%$ assurance level. Therefore, we can conclude there is a significant correlation between Gorgan High schools teacher's creativity and their Realistic \& Idealistic approach. In addition the results of t-student on Table 2 for idealistic attitude are $\mathrm{P}<0.05$ and $\mathrm{T}-4.903$ and we can conclude that there is a significant and positive correlation between idealism attitude and creativity and there is a negative and significant correlation between realism attitude and creativity.

Creativity=146.625+0.087 "Idealistic attitude” - (-0.335)” Realistic attitude”

\subsection{The second hypothesis}

The second hypothesis of this survey investigates whether realistic and idealistic teachers' creativity is more than those who do not have such attitudes or not. The proposed study of this paper uses tstudent to examine this hypothesis. Table 3 demonstrates the results of our investigation.

Table 3

T-test of two independent groups for testing the second hypothesis

\begin{tabular}{|c|c|c|c|c|c|c|c|}
\hline & \multirow[t]{2}{*}{$\mathrm{T}$} & \multirow[t]{2}{*}{ df } & \multirow[t]{2}{*}{ Sig. } & \multirow{2}{*}{$\begin{array}{l}\text { Mean } \\
\text { diff. }\end{array}$} & \multicolumn{2}{|c|}{ Assurance interval } & \multirow[t]{2}{*}{ Mean } \\
\hline & & & & & Low level & High level & \\
\hline Teachers with idealism - realism attitude & \multirow{2}{*}{15.32} & \multirow[b]{2}{*}{260} & \multirow[b]{2}{*}{000} & \multirow[b]{2}{*}{40.49} & \multirow{2}{*}{35.29} & \multirow{2}{*}{45.70} & 137.25 \\
\hline Teachers with no idealism-realism attitude & & & & & & & 96.75 \\
\hline
\end{tabular}

As we can observe from the results of the survey, t-student is statistically significance and we can confirm the second hypothesis.

\subsection{The third hypothesis}

The third hypothesis of the survey investigates whether idealistic teachers' creativity is more than those who do not have such attitudes or not. Table 4 demonstrates the results of our survey. The results of Table 4 confirm that there is statistically a meaningful difference between two groups creativity when the level of significance is five percent.

\section{Table 4}

T-test of two independent groups for testing the third hypothesis

\begin{tabular}{|c|c|c|c|c|c|c|c|}
\hline & \multirow[t]{2}{*}{$\mathrm{T}$} & \multirow[t]{2}{*}{$\mathrm{df}$} & \multirow{2}{*}{ Sig. } & \multirow{2}{*}{$\begin{array}{l}\text { Mean } \\
\text { diff. }\end{array}$} & \multicolumn{2}{|c|}{ Assurance interval } & \multirow{2}{*}{ Mean } \\
\hline & & & & & Low level & High level & \\
\hline $\begin{array}{l}\text { Teachers with idealism attitude } \\
\text { Teachers with no idealism attitude }\end{array}$ & 11.315 & 163 & 000 & 29.272 & 24.16 & 34.38 & $\begin{array}{l}150.91 \\
121.64\end{array}$ \\
\hline
\end{tabular}




\subsection{The fourth hypothesis: The relationship between gender and creativity}

Finally, the last hypothesis of the survey considers whether there is any relationship between creativity and gender or not. To test this hypothesis, we have performed Spearman correlation test and the results are summarized in Table 5 as follows,

\section{Table 5}

The results of Spearman correlation test between gender and creativity

\begin{tabular}{llcc}
\hline & & Gender & Creativity \\
\hline Gender & Spearman correlation & 1 & -0.341 \\
& Significant level & & 000 \\
& Number & 262 & 262 \\
\hline Creativity & Spearman correlation & -0.341 & 1 \\
& Significant level & 000 & 262 \\
\hline
\end{tabular}

The results of Table 5 show that there is a meaningful relationship between gender and creativity. Moreover, we have performed $\mathrm{Pi}$ correlation test, which yields $\mathrm{Pi}=0.725$ with P-value-0.004. The results of our survey indicate that women are more creative than men are.

\section{Conclusion}

In this paper, we have presented an empirical investigation to study the relationship between creativity and realistic-idealistic behaviors among teachers who were working in one of Iranian cities called Gorgan. The study considered four hypotheses. The first hypothesis of this survey investigated whether there was any relationship between Gorgan High schools teacher's creativity and their Realistic \& Idealistic approach or not. To answer this question, we have used regression analysis and the results of regression have indicated that there was a significant correlation between Gorgan High schools teacher's creativity and their Realistic \& Idealistic approach. The second hypothesis of this survey investigated whether realistic and idealistic teachers' creativity was more than those who did not have such attitudes or not and the results of our survey confirmed that there was, indeed, a meaningful difference between these two groups' creatively. We have also confirmed that idealistic teachers' creativity is more than those who do not have such attitudes. Finally, our survey has determined that female teachers were more creative than male teachers were.

\section{References}

Blumen-Pardo, S. (2002). Effects of a teacher training workshop on creativity, cognition, and school achievement in gifted and non-gifted second-grade students in Lima, Peru. High Ability Studies, 13(1), 47-58.

Crowther, F., Ferguson, M., \& Hann, L. (2008). Developing teacher leaders: How teacher leadership enhances school success. Corwin.

Rampaul, W. E. (1984). The relationship between academic achievement, self-concept, creativity, and teacher expectations among Native children in a northern Manitoba school. Alberta Journal of Educational Research, 30(3), 213-25.

Smith, L. M. (2005). A kind of educational idealism: integrating realism and reform. In The Roots of Educational Change (pp. 88-108). Springer Netherlands.

Troman, G., Jeffrey, B., \& Raggl, A. (2007). Creativity and performativity policies in primary school cultures. Journal of education policy, 22(5), 549-572.

Wiggins, J. (1999). Teacher control and creativity. Music Educators Journal, 85(5), 30-44.

Young, B.J. (1995). Career plans and work perceptions of preservice teachers. Teaching and Teacher Education, 11(3), 281-292. 